\title{
Capturing Agency and Voice in Research: A Critical Review of Studies of Youth Unemployment, Self-employment and the Informal Sector in Botswana
}

\author{
Latang Sechele \\ Dept. of Sociology, University of Botswana \\ P/Bag UB00705, Gaborone, Botswana \\ E-mail: sechelelt@mopipi.ub.bw
}

Doi:10.5296/ jsr.v6i1.7572 URL: http://dx.doi.org/10.5296/ jsr.v6i1.7572

\begin{abstract}
This article reviews literature on youth unemployment and self-employment as well as the informal sector in Botswana and the extent to which young people feature as agents in these studies. It pays attention to their areas of focus, research questions, and methodologies employed to understand the situation of youth unemployment and self-employment. One key finding coming from this review is that most of research portrays young people as overwhelmed by structural constraints and no attention is paid to their agency in the form of their perceptions of the situations they encounter as well as the strategies they use to respond to constraints and enablements. The article concludes by way of suggesting the methods and use of theoretical frameworks that would give a voice to young people as agents, which researchers should pay attention to in research designs.
\end{abstract}

Keywords: Agency, Youth Unemployment, Self-employment, Research Methodology 


\section{Introduction}

This article reviews literature on youth unemployment and self-employment in Botswana and the extent to which young people feature as agents in these studies. The paper conceives of agents, in Anthony Giddens terms, as people who are reflexive and capable of doing something about their structural constraints and enablements (Giddens, 1984). These capabilities, however, do not suggest agents always succeed in their efforts and that they are independent of the 'other' in their attempts to realize what they care most about. The paper proposes that paying attention to agency in research designs is crucial in ensuring that policies and programmes are relevant to the needs of the recipients or researched. It also helps policy makers, who seek to find solutions to the problems that young people face, to build on the strategies that they (young people) employ and suggest rather than rely entirely on the prescriptions of the researchers and experts. This means that the studies should be designed in such a way that, in addition to the dominant structural approaches, they clearly reflect what the researched are saying, thinking, and doing about their situations. Such challenges the traditional thinking that young people are too innocent, immature and incompetent to comment on decisions that affect them. The article focuses on specific studies of youth unemployment and self-employment as well as general studies of the informal sector in Botswana. It pays attention to their areas of focus, research questions, and methodologies employed to understand the situation of youth unemployment and self-employment. The article then concludes by way of revisiting some of the issues to stress the need for agency as well as suggesting the methods that seek to give a voice to young people as agents.

\section{Specific Studies of youth unemployment and self-employment}

One significant set of studies have investigated the extent to which the policies cater for the needs of young people. As some of these studies were undertaken almost at the time when these policies were being implemented for the first time, they could only reflect on their design and speculate whether young people would actually benefit. The Government of Botswana and the United Nations Development Programme/UNDP (2000) undertook a study on the situation of youth in Botswana covering such areas as education, employment and business. This nationwide study used desktop reviews, qualitative interviews and focus groups with stakeholders and unemployed young people. It sought to identify what is in place regarding youth development and the key problems/constraints to youth labour market entry in Botswana. The key constraints to youth labour market entry are identified as, lack of skills, lack of progression to senior secondary school, education curriculum which does not meet the needs of labour market, and bias against youth in the design of self-employment policies. The study recommends, among others, the formulation of youth-friendly labour market policies to tackle unemployment. Although this study reported having used interviews with stake holders and young people, this method is not reflected in the text. We do not know what young people themselves identify as constraints to self-employment and how they could be attended to. Young people are conceived as highly constrained, and no attention is given to their agency.

Moepeng and Dewah (2001) reviewed the extent to which Botswana citizen economic 
empowerment policies benefit disadvantaged groups of remote area dwellers, women, and youth. Key policies highlighted are the Financial Assistance Policy (FAP) and Arable Land Development Policy (ALDEP). The paper acknowledges government efforts at targeting certain groups of people, such as the remote area dwellers and women in these policies, albeit it decries lack of access to such programmes by the target groups. They lack, among others, the resources such as land and cattle (draught power) which could enable them to take advantage of these empowerment programmes. Whilst the authors did not question why the youth had not been targeted for assistance through these programmes, they suggested that they are most likely to be left out because they also lack resources and knowledge of existing enablements. This seminal paper proposes programmes that are youth-focused and those which could address the problem of lack of information and skills. However, data used here is based on the study of documents, and the youth were therefore not given an opportunity to express themselves and share their own views about employment policies and programmes.

An evaluation of the Out-of-School Youth Programme focusing on projects funded since the inception of the programme in 1999 was conducted by the Ministry of Labour and Home Affairs (Department of Culture and Youth, 2006). The purpose of this survey was to identify the extent to which the projects had been sustainable as well as the challenges that the funded entrepreneurs faced in the implementation of their projects. Part of the assessment was to see whether government youth officers interacted with the funded youth, as they should, and what forms of assistance they offered. The study covered 128 randomly selected out-of-school youth projects in fifteen locations that represented the different regions. The problems identified are, in order of severity, market competition, lack of appropriate equipment, financial constraints, no operational space, insufficient technical expertise, and others. It revealed that most of the youth officers had been informed about some of the problems during their visits and offered assistance in the form of technical advice, skills provision/training, and marketing. The authors did not go into details regarding these constraints except to quantify them, having used a questionnaire as a data collection instrument. What is also missing is to establish what the youth as active agents are doing in order to solve the challenges they face, apart from informing the youth officers about them. Another important area is to investigate what young people wish to see with regard to policy improvements. Seeking the views of beneficiaries is an important step towards formulating policies and programmes that are relevant to the circumstances that people face. It is also important to investigate the strategies that people use as a way of building on them in the formulation of national youth employment/self-employment strategies and support mechanisms.

Durham (2007) discussed new youth development projects in Botswana with a focus on economic empowerment/self-employment, and the extent to which such empowerment efforts run contrary to traditional forms of youth agency, built upon interdependent relations within the family and community. The author visited both non-government organizations and government officials to get a glimpse of their empowerment programmes. She also studied the policy design and requirements and concluded that access by the youth to self-employment programmes was most likely to be difficult due to high demands on 
applicants as well as complicated procedures. Moreover, she suggested that self-employment initiatives tend to promote individual agency exercised outside a collective body as they required young people to stand on their own and apart from their parents, which is contrary to Tswana culture. The main problem with this study is that there is no indication that the researcher actually consulted the youth that she is concerned about. In other words, this article presents how the researcher felt about the youth and not how the youth themselves viewed their constraints and opportunities.

Mukamugambira and Osei-Hwedie (2007) sought to understand the situation of youth unemployment by focusing on attitudes to manual work. Using a questionnaire on attitudes administered to 119 young people aged between 15 and 29 years working in construction companies, domestic service, and subsistence farming in Gaborone and three villages, the study sought to understand the factors that influence attitudes to manual work among young people in Botswana. It further sought to understand how these factors affect employment behaviour. Contrary to the cited studies of labour market, the authors found that many young workers had positive attitudes towards manual work. Motivating factors here are the significance of work in their lives, the need to contribute to the family, and desire to earn money. However, attitudes to manual work varied according to gender, education and age. More men than women had positive attitudes towards manual work. This study found that manual work is performed by people with some secondary education, meaning it is not confined to the un-educated. Whilst 57 percent of respondents were satisfied with and proud of their work, the study found that others were not happy with factors such as opportunities for advancement, freedom to do what they liked most, and salary increases. The study proposes that youth employment programmes must be designed in such a way as to address the dissatisfaction factors at work and also in collaboration with young people, employers and interested stakeholders, if manual work is to be made attractive to the unemployed youth. It further calls for programmes that would aim towards instilling positive attitudes towards manual work in society. Aside from exclusively using quantitative methods, which do not allow for full expression of the hidden voices, this study has made attempts to pay attention to youth agency. This is evident in its approach at studying attitudes and suggesting that policy makers should get the views of young people in order to address dissatisfaction factors at work. It would have been better to incorporate qualitative methods in the study design as well.

Other studies on youth and self-employment focus on vocational training. The most well known formal training programme for the youth is Brigades training. This training is designed to accommodate young out-of-school people between the ages of 18 and 25 years (Hoppers, 1986; Mafela and Fidzani, 1995; and Mwansa and others, 1994). Livingston (1985) undertook a study, under the auspices of the ILO, to assess youth employment and training programmes in Botswana. The objectives of the study were to: a) analyse the factors affecting employment prospects for school-leaving youth in the formal sector and their absorption into self-employment in the informal and agricultural sectors of the economy and (b) assess the effectiveness of the existing youth employment programmes and policies. His methodology was documentary; he used government documents such as the national census reports, 
manpower projections, labour force surveys, and some tracker studies on school leavers and graduates of vocational institution's conducted in the 1970s.

Livingston (1985) suggested that structural or macro-economic factors, such as the weak informal sectors and traditional agriculture were a hindrance to the development of alternative employment strategies other than paid work in the formal sector. He was critical of Brigades training in that it did not lead to self-employment as intended. Training was conducted in such as way that it prepared young people for paid formal employment. As reflected in the objectives of the study and the methods of data collection, being documentary and statistical records, the author did not have an opportunity to interact with young people. The study did not focus on young people's perceptions about constraints to labour market entry, which captures their agency.

Hoppers' (1986) study, like that of Mafela (1995), focused on the relationship between training and self-employment in Botswana and Zambia. The methodology used is not clearly spelt out in this study. But in reading the text it appears that he used policy documents and past tracker studies of graduates of Brigades institutions. The voice of young people is absent in this research report. This review will focus on the Botswana part of the study. His emphasis was on the Brigades training, which exclusively caters for young people in Botswana. The key issue was whether the Brigades promote self-employment and which aspects of Brigades training should be encouraged. Theoretically Brigades training emphasises production and self-employment. But Hoppers (1986) argues that Brigades training has tended to emphasise training in technical skills, such as auto mechanics and carpentry, which are in high demand in the formal sector, rather than those that could provide self-employment, such as sewing, knitting and horticulture. This is also reflected in the government's selective approach of subsidising only students that pursued courses in skills such as building and engineering which were in high demand in the formal sector, to the exclusion of those that were geared towards self-employment such as horticulture and textiles. He also found that there was less emphasis on business or entrepreneurial skills training necessary to prepare students for self-employment. The entrepreneurial skills were taught in the evenings and not during the day, which makes them appear as if they are insignificant. Practically, therefore, Brigades training tended to prepare students for formal employment rather than self-employment. Upon graduation, the majority of students found work in the formal sector where there is high demand for their skills. Those that attempted to start businesses were reportedly doing badly in the market due to competition from well established companies. This was compounded by lack of experience and working capital. Those who appeared to do well had worked for some established companies prior to starting their businesses and thus accumulating capital and experience. Those who managed to be self-employed were older youth.

Hoppers (1986) acknowledged that the government of Botswana had come up with increased support for small scale productive enterprises, as called for under the fifth national development plan. While these forms of support presented opportunities for young people to start their own projects, he found no evidence that this ever happened. He dismissed the general perception that young people might not be interested in self-employment as 
demonstrating a lack of interest in youth programmes. He regarded the major problem as failure by the government policy makers and implementers to give young people priority when it comes to distributing scarce resources. He called on government agencies to assist young people to undertake production activities at a higher level than subsistence through training at the Brigades.

A more recent study on youth was undertaken by Mwansa and Mufune (1994) on youth enterprise schemes in the Southern African Development community countries with a focus on Botswana, Swaziland and Zambia. Its focus was more on the working of institutions and their internal problems with the official given a voice. The objectives of this study included 'a) studying specific youth enterprise schemes (emphasising their prospects, problems and solutions); b) consulting with experts in areas of youth enterprise (in government, non-governmental and academic sectors); c) interacting with the youth who are actively engaged in those enterprises; and d) seeing what role youth enterprises can play in increasing literacy, population education and amelioration of the situation of young females' (p.240). One of the major findings of this study is that in Botswana, emphasis on formal employment in technical schools and informal training schemes has been a major hindrance to youth self-employment. Despite the fact that one of the objectives of the study was to interact with the youth engaged in the youth schemes, the authors did not reveal what the youth said about these schemes. We learn more about the problems that affect the institutions, including managerial and financial constraints, which might have been revealed by the officials. Therefore one can conclude that this study was not more about the youth themselves but the institutions.

Fidzani and Mafela (1995) evaluated the effectiveness of the Brigades as Botswana's providers of technical and vocational education and training. This was a tracker study of Brigade graduates. The key question was whether the Brigades were training the right people for the right trades with the right skills for the right jobs. In addressing this question, the study sought to find out whether young Brigades graduates find work and how the chances differ in terms of gender; the extent to which the skills are relevant to the needs of the employers and the economy; the extent to which the skills acquired during training are utilised; and whether the Brigades train enough people (quantity). The study therefore investigated issues around work and employment, diversification of training areas, quality and quantity of training. In addressing work and employment, the researchers reflected one of the objectives of the Brigades being to promote self-employment among young people. The study mailed a questionnaire to 144 graduates, comprising 114 males (79 percent) and 30 females (21 percent) who completed training between 1989 and 1991. A questionnaire was also mailed to the employers to obtain their views on the performance of graduates at work. Of the graduates that found work, only 18.1 percent were in self-employment, and the rest were employed mostly in government jobs. Self-employment was highest among females, mainly using garment industry skills, which were not skills that were highly needed in the formal sector at that time. The authors did not talk to those employed in the formal sector to establish the reasons for their preferences for formal employment and not self-employment. However, they speculated that entry into self-employment could be difficult for new 
graduates as it may require availability of capital, confidence and experience, which they normally do not have. Structural factors such as the performance of the economy and the existence of government support schemes may facilitate or hinder the extent to which people may engage in self-employment. These are the key issues that needed to be investigated by researching why young people have a preference for formal employment over self-employment. This study lacks the voice of, and focus on, the self-employed, even though a significant 18.1 percent were self-employed. The authors tended to focus on young people in the formal sector. We do not know how the self-employed viewed the relevance of their training to their work situations, and their successes or problems they were facing. The study is therefore biased towards those who found work in the formal sector.

\section{General Studies of Informal Sector Entrepreneurs}

The need to create sustainable employment opportunities in order to alleviate problems of poverty, unemployment, and social inequality have been emphasised by the government of Botswana in its development programmes. As part of a strategy to create employment, the informal sector and small scale enterprises have been targeted for promotion (Sunny, 1994; Briscoe, 1995). Since the 1980s, a number of independent and government studies on the informal sector have been commissioned. Emphasis has been placed on identification of constraints of the informal sector and how it could be assisted to provide a base for economic diversification and employment creation.

A study by Alexander and others (1983), which was commissioned by the Government of Botswana and conducted between November 1982 and March 1983, represents the first comprehensive study on the informal sector in Botswana. The aim of the study was to provide baseline information on the nature of the informal sector, which could be used as the basis for the design and implementation of policies and programmes to promote employment creation. The terms of reference further required the consultants to highlight the problems affecting women entrepreneurs. No special attention was paid to young people. It was hoped that this study would also be useful in promoting the inclusion of informal sector activities in the Labour Force Surveys, and since then, all Labour Force Surveys have tried to measure informal employment. The study used a questionnaire that was administered to a sample of 298 respondents, selected both randomly (for common businesses) and purposively (rare businesses). In order for the consultants to understand more about the nature of informality, they also visited the survey sites, spent a night there, and made some observations. During the course of the survey the researchers held informal talks with some entrepreneurs, who were asked to share information about the nature of their work, particularly telling stories about their business progress and problems.

Among some of the findings of the study was that the informal sector had major limitations in the provision of sustainable employment opportunities in Botswana. This is attributed to the fact that Botswana's informal sector was very young as compared to other countries and was marred by a myriad of problems in the area of business management, competition with formal enterprises, lack of diversification of products and services, poor quality of products, and shortage of business premises. The common story theme emerging was that of lack of 
progress, and entrepreneurs appeared to be discouraged in their business pursuits.

In terms of ownership of the informal enterprises surveyed, the study found that more than half of the businesses were owned by women. It also revealed the average age of people owning businesses as 43.5 years, with the majority aged between 31 and 60 years. There was no evidence found for young people participating in large numbers in the informal sector in the 1980s, and this was contrary to the situation in other African countries where young people were doing so. This was in spite of the fact that the youth unemployment rate in the 1981 census was recorded as 18.5 percent, which was significantly higher than the national average of 10 percent (Livingston, 1985). The report suggests that low levels of young people's participation in the informal sector, particularly business ownership, could be explained in terms of their preferences for formal employment, and especially if better schooled than the adults. It is worth noting that the report argues that the informal sector is a refuge of people without schooling and those with very low levels of education. It further argues that at that time, there were opportunities for young people to seek and find jobs outside Botswana. This raises questions of attitudes towards informal employment and how young people's perceptions of the formal job prospects affect their entry in self-employment. However, this could not be investigated with the youth themselves because the study was not meant to assess these issues. Instead, in order to fulfil one of the terms of reference, this report went on to study the constraints faced by women entrepreneurs. It found that women were in a subordinate position within Botswana society and both customary and modern marriage laws worked against their progress in businesses.

The Daniels and Fisseha (1992) study aimed to assess the following: i) the size and composition of the informal sector ii) the structure of employment among informal enterprises; iii) constraints limiting the development of the informal sector and problems identified by entrepreneurs that hinder enterprise growth; iv) linkages of the informal sector to traditional agriculture and formal sectors of the economy; and v) sources of informal enterprise finance (Daniels and Fisseha, 1992:1). In addition to these objectives, the study collected information on the characteristics of the entrepreneurs with a focus on age, education, prior activities, and experiences. Although this study was designed in such a way that entrepreneurs highlighted their constraints to self-employment, no attention was given to how they responded to such constraints. The dominant tone to portray the entrepreneurs was that of constrained agents which was set out initially in the objectives of the study. Nevertheless, the study noted constraints to self-employment as lack of finance, fewer linkages with the formal sector and lack of growth of enterprises.

Sunny and Babikanyisa (1994) collected and analysed information on the size, composition, sources of financing, linkages of the informal sector and other sectors of the economy in seven urban communities in Botswana. In addition the study looked at constraints of the informal sector. This is a quantitative study relying on a survey (questionnaire). Among the principal findings were that the informal sector enterprises were predominantly owned and run by women ( 68 percent); that the sector lacked access to credit, and suffered from too much competition, lack of space, and lack of managerial ability. Owner savings were the major source of finance for enterprises. Even though young people constituted the majority 
of those who were unemployed and appeared to be marginalised in the formal labour market, no special attention was given in this study to either age or the characteristics of youth businesses. In this report, women were a focus of special attention in terms of outlining their business characteristics and constraints that affected their operations.

Ntseane (2004) carried out an in-depth interview on 13 female small business entrepreneurs in the formal sector, selected through snowball sampling, to determine the contextual and personal factors that facilitate or impede women's small business, and the common processes that women in Botswana typically go through to build a successful business. This independent (academic) research was undertaken in 2003 in Francistown, which is the second city of Botswana. The indicators of business success for this study included increases in annual revenues and investment expenditures, increase in the number of employees from one to ten or more, and status movement from an informal (unregistered) to formal (registered business). Although these were formal sector entrepreneurs, their views were based on their previous experiences as informal sector entrepreneurs. Ntseane (2004) found that all women in this study traced the emergence and development of their businesses from crises such as teenage pregnancy, dropping out of school and family break-up that compelled them to generate income of some sort through informal business activities. Ntseane (2004:39) noted: 'Faced with the need for money, participants realised that they had skills acquired from the family, observation, or common sense, which they could use to start a business'. The women, however, had to contend with cultural factors, such as having to get the consent of their fathers to set up a business or undertake business trips. They were also constrained by their domestic roles such as supporting children and other family members. In order to overcome or minimise these constraints, and ultimately grow their businesses to reach the status of the formal sector, the women entrepreneurs used innovative strategies such as: a) linking up the business with household or family members and b) non-competitive networks with other business women for sharing ideas and undertaking collective action to change government legislation.

Ntseane study is useful in understanding women's experiences in the formal and informal sectors, as well as the strategies they use to overcome barriers to business success. It helps us to further understand that structure functions as a constraint and an enablement. Ntseane does not present women as entirely overwhelmed by structure, but she demonstrates the significance of agency in their response to enablements and constraints. It would be important however, to refocus on young people to understand if there are any cultural factors affecting their entry into business and what constraints they face in the market as self-employed entrepreneurs.

Somolekae (1989) focused on women owned enterprises in the informal sector and small scale entrepreneurs and sought to provide a profile of women entrepreneurs and their businesses, as well as to identify their problems. This ILO commissioned study covered two groups of women whose characteristics were compared: 72 existing entrepreneurs and 36 women with an expressed interest to go into business. The study used two sets of questionnaires and a focused behavioural interview. The study was conducted in Lobatse and Gaborone urban areas. Somolekae found no significant differences between the family 
backgrounds of the potential entrepreneurs and the self-employed, as they both came from poor agricultural backgrounds with none of their parents engaged in business. Neither group had assets. The only differences were that the potential entrepreneurs were young and unmarried, whist the self-employed were older and married. Somolekae concluded that the self-employed ones might have had an advantage of being assisted by their resourced husbands to set up their businesses, while the single ones had difficulties acquiring start-up capital. However, the study did not seek to understand the sources of capital for those who were already in business. Specific business problems that affected women entrepreneurs were a) difficulties in finding customers since they had to operate from home in order to fulfil their domestic functions of taking care of the family; b) too many responsibilities at home was not consistent with the business demands; c) women not being well informed about government training and self-employment schemes; d) legislation that required women to get the consent of their husbands when applying for bank loans were a hindrance to successful businesses. The study has paid attention to structural constraints, presenting women as constrained, but does not investigate their agency. However, this study unearthed women's specific challenges because the author focused specifically on women. This underscores the need to identify the youth-specific challenges.

\section{Methodologies for Bringing out the Voices of Young People}

Three ways of capturing agency and to a certain extent structural constraints in studies about youth self-employment and unemployment are suggested as follows:

First is the use of theoretical frameworks that capture both structural and agentic dimensions. It has surfaced in this review that many researchers about youth unemployment and self-employment in Botswana, especially those that are non-academic, never pay attention to the use of theoretical frameworks in undertaking their research. The concentration has always been on specific research methods, such as questionnaires. Yet it is important to use theories in order to serve as cognitive maps towards what one intends to research. Furthermore, by default rather than design, attention has always been placed more on capturing the constraining structures to youth unemployment and self-employment to the subordination of young people's agency. While studying structural constraints is important, it is equally important to pay attention to human agency. One of the theoretical frameworks that look at the agentic dimensions without losing sight of structural elements of action is structuration theory. In his study of youth self-employment and unemployment in Botswana, Sechele (2011) used such theory to understand young people's internal and external structural constraints and enablements to employment, such as the policy environment, employment histories, dispositions and social backgrounds, as well as agency in the form of young people's labour market aspirations and perceptions and practical and imaginative response to such constraints. Both research questions and the actual questions addressed to the subjects were formulated in such a manner as to capture these dimensions. This enabled him to have a broader and well-rounded mind in thinking about and capturing situations that young people face in the labour market.

Second, aside from using theoretical frameworks, attention must be paid to the use of 
methods that allow for full expressions of viewpoints, enabling participants to tell stories about their experiences. In the study highlighted above, Sechele (ibid.) used focus groups, life story, and qualitative interviews to capture agency. Some of the methods, such as focus groups, enabled full discussions of certain topical areas and interactions between young people facing similar situations. They were, for instance, able to articulate and debate issues well as well as make suggestions as to how structural constraints to self-employment could be weakened. They were also able to outline areas where they have power to change their situations as well as those in which they would need external intervention through government agencies.

Third, attention must also be paid to creating an environment that is conducive for full and free expression of viewpoints. For example, youth should not be interviewed in the presence of their parents. In some issues the parents could be perceived as major players that to some extent contribute to the worsening of children's predicaments. However, this cannot be articulated by victims in the presence of perceived perpetrators.

\section{Conclusion}

Although youth unemployment is recognized as a problem that needs urgent attention in Botswana, there has been very little research on young unemployed people. Most research on the self-employed people has been on adults, and some of it has specific focus on women as a disadvantaged group (Alexander, 1983; Somolekae, 1989; Sunny and Babikanyisa, 1994; Ntseane, 2004). The existing research on youth unemployment and self-employment focuses much more on policies and institutional effectiveness. These studies conclude that policies and programmes have not been very youth-friendly. In the end the researchers come up with recommendations on what could be done to make institutions more effective in addressing the needs of young people. It is never clarified whether young people, as agents, have suggested anything as well as the extent to which they can do so. What is missing are studies which investigate in depth the views and lives of young unemployed and self-employed people. An in-depth study using qualitative research methods, such as focus groups and in-depth interviews, which would give the youth a platform for expression, is needed. Moreover, this would avoid a situation whereby in policy designs and the use of less interactive research methods, '... children have been 'spoken for' and often misunderstood or misrepresented' (Slim and Thompson, 1993:73). The use of theoretical frameworks such as structuration would assist in capturing how the youth are constrained and enabled as well as how they respond to their situations as agents. Another method for capturing agency suggested in this review is creation of a conducive environment for young people to express their views without the fear of being victimised by adults.

\section{References}

\section{Government Sources}

Alexander, E. Mbere, N. (1983). The Informal Sector in Four Botswana Communities.

Gaborone: Applied Research Unit, Ministry of Local Government. 


\section{Macrothink}

Journal of Sociological Research

ISSN 1948-5468

2015, Vol. 6, No. 1

Daniels, L. Fisseha, Y. (1992). Micro and Small-scale Enterprises in Botswana: Results of a Nationwide Survey. Gaborone: USAID/Ministry of Finance and Development Planning.

Department of Culture and Youth. (2006). Needs Assessment Survey Report on Youth Projects that have been Funded through the Out-of-School Youth Programme. Gaborone: Ministry of Labour and Home Affairs.

Government of Botswana/ United Nations Development Programme (2000). Situation Analysis Report on Youth in Botswana. Gaborone: Ministry of Labour and Home Affairs.

Fidzani, N.H. Mafela, L. (1995). A Report of the Tracer and Evaluation Study of the Botswana Brigades. Gaborone: Botswana Government Printer

Moepeng, P. Dewah, Z. (2001). 'Empowering the Poor and Other Disadvantaged Groups', Citizen Economic Empowerment Workshop, and July 2001. Gaborone: Ministry of Finance and Development Planning. Pp.136-147

\section{Academic and Private Sources}

Briscoe, A. (1995). Small Business Support in Botswana. Gaborone: Morula Press.

Durham, D. (2007). Empowering Youth: Making Youth Citizens in Botswana, Cole, J.

Durham, D. (ed.). Generations and Globalization: Youth, Age, and Family in the New World Economy. Bloomington: Indiana University Press.

Giddens, A. (1984). The Constitution of Society: Outline of the Theory of Structuration. Cambridge: Polity Press.

Hoppers, W. (1986). After Training, What? Youth Training and Self-employment in Botswana and Zambia. London: Commonwealth Secretariat.

Livingston, I. (1985). Youth Employment and Youth Programmes in Africa: Botswana. Geneva: International Labour Office.

Mukamugambira, P. Osei-Hwedie, K. (2007). Factors Influencing Attitudes of Botswana Youth towards Manual Work: Implications for Employment. Journal of Social Development in Africa, 22,107-130.

Mwansa, L.K, Mufune, P. Osei-Hwedie, K. (1994). Youth Policy and Programmes in SADC countries of Botswana, Swaziland and Zambia: a comparative assessment. International 
Social Work, 37, 239 - 263.

Ntseane, P. (2004). Being a Female Entrepreneur in Botswana: Cultures, Values and Strategies for Success, Gender and Development, 12 (2), 37-43

Sechele, L.T. (2011). Youth Unemployment and Self-employment in Contemporary Botswana. PhD Thesis (Unpublished): University of Essex.

Slim, H., Thompson, P. (1993). Listening for a Change: Oral Testimony and Community Development. Philadelphia, PA: New Society Publishers.

Sunny, G. Babikanyisa, V. (1994). The Second Best: The Role and Constraints of the No-n Formal Sector in Botswana. Gaborone: University of Botswana. 